\title{
Limbic Encephalitis Associated With GAD65 Antibodies: Brief Review of the Relevant literature
}

\author{
Maude-Marie Gagnon, Martin Savard
}

\begin{abstract}
Recently, many cases of autoimmune limbic encephalitis with positive GAD65 (glutamic acid decarboxylase) antibodies have been described in the scientific literature. However, it remains an understudied topic of great relevance to practicing neurologists. Thus, we report here a review of published cases, in English, of autoimmune limbic encephalitis with this type of antibodies, focusing on presenting symptoms and signs, associated conditions, and findings upon investigation. We also report treatment responses. We aim to offer a better description of the clinical spectrum of autoimmune limbic encephalitis associated with GAD65 antibodies as well as to expose its paraclinical features and outcome.
\end{abstract}

RÉSUMÉ: Au cours des dernières années, plusieurs cas d'encéphalite limbique avec anticorps GAD65 (glutamic acid decarboxylase) ont été décrits dans la littérature. Néanmoins, il s'agit d'un sujet relativement peu connu, mais qui s'avère pertinent à bien connaître pour les neurologues praticiens. Ainsi, nous proposons une revue des différents cas publiés, en anglais, d'encéphalite limbique auto-immune associés à cet anticorps. Celle-ci se concentre sur la présentation clinique, les conditions associées de même que les trouvailles à l'investigation. De surcroît, nous proposons une revue des traitements utilisés et de leurs réponses. Cet article a pour objectif premier d'obtenir une meilleure description du spectre clinique de l'encéphalite auto-immune avec anticorps GAD65 et, dans un second temps, d'exposer ses caractéristiques paracliniques ainsi que son évolution.

Keywords: cognitive impairment, CNS inflammation, immune system, neuroimmunology, neuroinflammation, neurology - clinical, seizures, status epilepticus

doi:10.1017/cjn.2016.13

Can J Neurol Sci. 2016; 43: 486-493

\section{BACKGROUND}

Limbic encephalitis (LE) was first described in the 1960s. ${ }^{1}$ It is a disorder affecting the medial temporal lobe of the brain and can be explained by infective and systemic autoimmune etiologies. It can also be associated with neuronal antibodies related to cancer (in paraneoplastic LE) ${ }^{2}$ or not (in nonparaneoplastic autoimmune LE). ${ }^{3}$ Recently, an increasing number of valuable autoantibodies have been identified, including glutamic acid decarboxylase 65 (GAD65) antibodies.

LE is characterized by subacute development of short-term memory loss, seizure, or psychiatric symptoms suggestive of limbic involvement. It is combined with inflammatory findings in cerebrospinal fluid (CSF) or temporal abnormalities on magnetic resonance imaging (MRI) or electroencephalogram (EEG). Criteria sets have been suggested, including clinical and radiological findings. ${ }^{4-6}$

GAD is crucial for the conversion of glutamic acid into gamma aminobutyric acid (GABA), which is the major inhibitory neurotransmitter of the central nervous system. Antibodies against this enzyme possibly cause an imbalance resulting in the outweighing of excitatory neurotransmitters such as glutamic acid and aspartate, which induce a neuronal hyperexcitability. ${ }^{7}$ They are among the autoantibodies against intracellular components. GAD65 antibodies are markers of type 1 diabetes $^{8}$ and are found in high titers $(>1000 \mathrm{U} / \mathrm{ml})$ in various neurological pathologies such as stiff-person syndrome (SPS) ${ }^{9}$ pharmacoresistant epilepsy, ${ }^{10}$ cerebellar ataxia, ${ }^{11}$ and progressive encephalomyelitis with rigidity and myoclonus. ${ }^{12}$ In the literature, characteristics of SPS are well described, whereas autoimmune LE with these type of antibodies remains an understudied topic.

We report here a review of published cases, in English, of autoimmune LE with GAD65 antibodies, focusing on clinical presentation of initial symptoms and signs, associated conditions, and findings upon investigation, including other autoantibodies results. Treatment responses are also reported. The purpose is to better define the clinical spectrum of autoimmune LE associated with GAD65 antibodies to raise awareness of this disease and expose its outcome.

\section{Methods}

We conducted a search on Medline for articles published in English between August 1998 and August 2014 and using the keywords "encephalitis" and "GAD" or "glutamic acid decarboxylase." A back-search of reference lists from retrieved publications was also conducted to identify other potentially relevant articles. The year 1998 was chosen as the starting point because the first relevant case was reported at that time. ${ }^{36}$ Titles and abstracts were screened and articles were included according to their relevance to the entry criteria. If an abstract was not

\footnotetext{
From the CHU de Québec - Neurological Science, Quebec, Canada.

Received December 6, 2015. Final Revisions Submitted December 21, 2015 Correspondence to: Maude-Marie Gagnon, Enfant-Jésus Hospital - Neurology, 1401, 18th Street Quebec, Quebec G1J 1Z4, Canada.

Email: maude-marie.gagnon.1@ulaval.ca
} 
available, the entire article was screened. We selected clinical case reports and case series reporting positive GAD65 antibodies using the term "encephalitis" (in titles, abstract, or text). We also included observational studies with prospective or retrospective analysis of sera or CSF of patients with diagnosis of LE if clinical features were available. There were no special requirements for positive CSF GAD65 antibodies in patients with diabetes type 1 or for details concerning clinical features, treatment, or outcome. We included cases from adult and pediatric populations (Table 1).

Clinical details were extracted and then revised by one reviewer (M-MG). Before review, specific variables were identified as general characteristics, clinical manifestations, MRI and EEG findings, concomitant systemic autoimmune disorders and cancer, and outcome and autoantibodies findings. In regard to clinical manifestations, we assumed that the signs or symptoms that were not mentioned in the case description were absent (as opposed to other variables considered as "not available" when they were not explicitly mentioned). In regard to MRI findings, "abnormalities" referred to T2/fluid attenuated inversion recovery hyperintensities (with or without contrast enhancement). Spikes, sharp waves, electrographic seizures, and status epilepticus or "epileptiform activity" on EEG were included as epileptiform abnormalities. Data were stratified into four groups for outcome, from full recovery to death. The outcome was considered as an "improvement" when improvement of the initial symptoms was observed at the time of the last available follow-up. A relapse was considered if there was a recurrence of symptoms or the appearance of new symptoms related to LE after diagnosis of LE and a period of at least 1 month of significant improvement (after treatment or not). For demographic, clinical, and outcome differences between groups, Fisher's exact test was used. Finally, we did not contact authors to obtain further information (more details on variables in Supplementary Appendix 1).

\section{RESUlts}

We identified a total of 58 cases (from 31 articles) in adult $(\mathrm{n}=37)$ and pediatric $(\mathrm{n}=21)$ populations.

\section{Table 1: Search process flowchart}

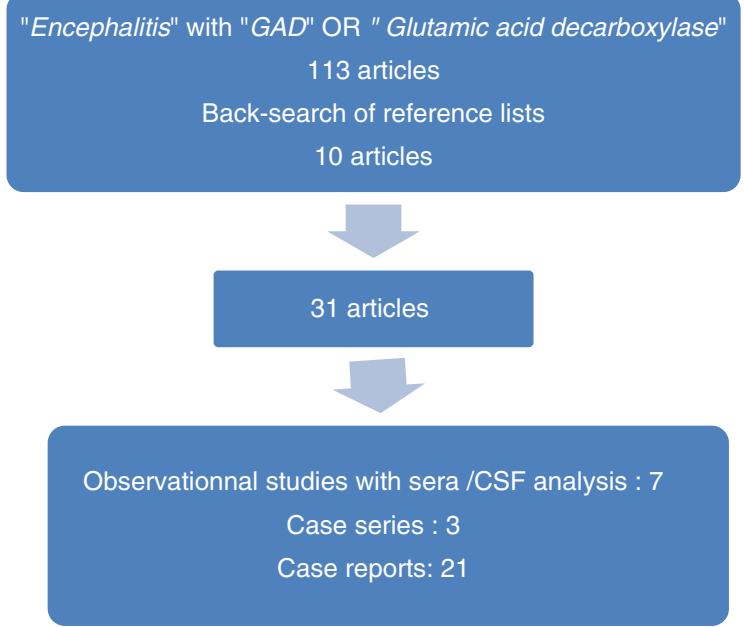

\section{General Characteristics}

Most cases were young adult patients, but a child as young as 1 year old ${ }^{15}$ has also been reported. The majority of patients were women $(59 \%, 34 / 58)$; however, in the pediatric population, there was a slight predominance of males $(57 \%, 12 / 21)$.

Systemic autoimmune disorders appeared to be frequent $(48 \%$, $22 / 46)$, particularly diabetes $(35 \%, 16 / 46)$. Psoriasis, ${ }^{19}$ common variable immune deficiency, ${ }^{22}$ celiac disease, ${ }^{21,38}$ and autoimmune thyroiditis $^{14,16,21,28,38,40,41}$ were also reported. For six cases, more than one autoimmune condition ${ }^{14,21,28,38,41}$ was described. Cancer was reported in $10 \%$ of cases $(10 \%, 6 / 58)$, with cancer workup not explicitly done in 16 cases $^{15,20,22,25,26,32,35,38}(14 \%, 6 / 42)$. They were men from 38 to 70 years old with a mean age of 61 years. Malignancies were small-cell lung carcinoma $(67 \%, 4 / 6)^{28,30,39}$ and malignant thymoma $(33 \%, 2 / 6)$ (Table 2). ${ }^{29,31}$

\section{Clinical Features}

Seizures were the most frequent manifestation $(97 \%, 56 / 58)$; they were reported in all cases except for two. ${ }^{17,28}$ Status epilepticus was reported in $24 \%(24 \%, 14 / 58)$, which was generally refractory and treated with multiple anticonvulsive drugs, ${ }^{14,15,18,22,24,25,37,43}$ and only one had concurrent neuronal antibodies (GABA A receptor $\left.\left[\mathrm{GABA}_{\mathrm{A}} \mathrm{R}\right], 7 \%, 1 / 14\right) .{ }^{14}$ One case reported a certain efficiency of treatment with ketamine in a 21 -year-old woman with refractory status epilepticus. ${ }^{18}$ Opercular

Table 2: General characteristics ${ }^{14-44}$

\begin{tabular}{|c|c|}
\hline Age & $1-70$ years \\
\hline \multirow[t]{2}{*}{ Pediatric population } & $1-17$ years \\
\hline & Median age : 10 years \\
\hline \multirow[t]{2}{*}{ Adult population } & 19-70 years \\
\hline & Median age $: 39.5$ years \\
\hline \multirow[t]{3}{*}{ Female sex } & $59 \%(34 / 58)$ \\
\hline & Pediatric population $43 \%(9 / 21)^{*}$ \\
\hline & Adult population $73 \%(19 / 26)^{*}$ \\
\hline \multirow[t]{13}{*}{ Autoimmune diseases } & $48 \%(22 / 46) \dagger$ \\
\hline & Cases with: \\
\hline & Diabetes only: $50 \%(11 / 22)$ \\
\hline & Other autoimmune diseases only: $27 \%(6 / 22)$ \\
\hline & Both diabetes and other autoimmune diseases: $23 \%(5 / 22)$ \\
\hline & Cases with: \\
\hline & Thyroiditis: $73 \%(8 / 11)$ \\
\hline & Psoriasis: $9 \%(1 / 11)$ \\
\hline & Commune variable immune deficiency: $9 \%(1 / 11)$ \\
\hline & Celiac disease: $18 \%(2 / 11) \ddagger$ \\
\hline & Cases with: \\
\hline & Diabetes $35 \%(16 / 46)$ \\
\hline & Type 1: $94 \%(15 / 16) ;$ type $2: 6 \%(1 / 16)$ \\
\hline Cancer & $10 \%(6 / 58)$ \\
\hline
\end{tabular}

*Total of 47 patients with both known age and sex.

$\dagger$ Total of 46 patients with known autoimmune status.

$\ddagger$ One case had two autoimmune diseases. 
Table 3: Clinical features ${ }^{14-44}$

\begin{tabular}{|c|c|}
\hline Seizures & $97 \%(56 / 58)$ \\
\hline Cognitive impairment & $66 \%(38 / 58)$ \\
\hline Memory & $59 \%(34 / 58)$ \\
\hline Other than memory & $40 \%(23 / 58)$ \\
\hline Orientation & 7 cases \\
\hline Language & 7 cases \\
\hline Executive functions & 3 cases \\
\hline Attention/concentration & 3 cases \\
\hline Praxia & 2 cases \\
\hline Confabulation & 1 case \\
\hline Psychiatric symptoms & $28 \%(16 / 58)$ \\
\hline Depression & 6 cases \\
\hline Change in behavior or personality & 6 cases \\
\hline Psychomotor agitation & 5 cases \\
\hline Perception disorder (hallucinations, delusions) & 4 cases \\
\hline Anxiety & 2 cases* \\
\hline Fever & $14 \%(8 / 58)$ \\
\hline Dysautonomia & $12 \%(7 / 58)$ \\
\hline Cerebellar manifestations & $7 \%(4 / 58)$ \\
\hline Headache & $5 \%(3 / 58)$ \\
\hline
\end{tabular}

*More than one psychiatric symptoms in five cases.

myoclonic-anarthric status epilepticus was described in one patient. ${ }^{37}$ Epilepsia partialis continua was described in three cases, ${ }^{14,25,26}$ whereas dysgeusia/dysosmia was described in two. ${ }^{14,44}$

Memory impairment was the second most frequent manifestation $(59 \%, 34 / 58)$. Impairment of other cognitive functions was also common $(40 \%, 23 / 58)$. Disorientation, dysexecutive syndrome, and language problems were reported. Confabulation and apraxia were reported in one ${ }^{42}$ and two cases, respectively. ${ }^{32}$ Psychiatric symptoms were described in $28 \%$ of

Table 4: Tested antibodies ${ }^{14-44}$

\begin{tabular}{l|l|c}
\hline Antibodies & Positive results* & $\begin{array}{c}\text { Proportion of testing for } \\
\text { other antibodies }\end{array}$ \\
\hline GAD65 antibodies in CSF & $\mathrm{n}=38,66 \%(38 / 58)$ & - \\
\hline $\begin{array}{l}\text { GAD65 antibodies in } \\
\text { serum only }\end{array}$ & $\mathrm{n}=18,31 \%(18 / 58)$ & - \\
\hline $\begin{array}{l}\text { GAD65 antibodies in } \\
\text { serum and CSF }\end{array}$ & $\mathrm{n}=35,60 \%(35 / 58)$ & - \\
\hline GABA $_{\mathrm{A}} \mathrm{R}$ & $\mathrm{n}=5,100 \%(5 / 5)$ & $9 \%$ \\
\hline GABA $\mathrm{B}$ & $\mathrm{n}=3,19 \%(3 / 16)$ & $28 \%$ \\
\hline AMPAR & $\mathrm{n}=0,0 \%(0 / 11)$ & $19 \%$ \\
\hline VGKC & $\mathrm{n}=3,6 \%(3 / 48)$ & $83 \%$ \\
\hline NMDAR & $\mathrm{n}=0,0 \%(0 / 41)$ & $71 \%$ \\
\hline Onconeuronal antibodies & $\mathrm{n}=0,0 \%(0 / 38)$ & $66 \%$ \\
\hline
\end{tabular}

*Number of cases with antibodies explicitly tested. cases $(28 \%, 16 / 58)$, with mainly depression and behavior or personality changes. Concerning movement disorders, myoclonus $^{20,26,37}$ (three cases) and facial cramps $^{14}$ (one case) were described. Mild generalized rigidity was described once ${ }^{24}$ and concurrent diagnosis of SPS was made in one patient. ${ }^{14}$ Cerebellar manifestations were reported in four cases. ${ }^{22,24,35,37}$ Headache was rare and described only in pediatric cases. ${ }^{15,44}$ Hyperphagia ${ }^{17}$ gaze-evoked nystagmus, ${ }^{16}$ and tinnitus with facial cramps ${ }^{14}$ were manifestations reported in one case each (Table 3 ).

\section{Imaging and Paraclinical Features}

Brain MRI was reported abnormal in $78 \%$ of cases $(78 \%$, $45 / 58$ ); involvement of temporal lobes was usual and described in 34 cases $(59 \%, 34 / 58)$. Multifocal abnormalities were present in nine cases $(16 \%, 9 / 58)$. In seven, the initial brain MRI was reported normal. ${ }^{18,19,21,25,35,37,38}$ EEG results were available for 35 cases. Epileptiform abnormalities were found in 27 cases $(77 \%, 27 / 35)$, with temporal involvement most frequent (70\%, 19/27). Multifocal $(22 \%, 6 / 27)^{14,15,25,35,44}$ and generalized $(7 \%, 2 / 27)^{15,24}$ epileptiform abnormalities were also described. On lumbar puncture, pleocytosis was reported in 11 cases $(27 \%, 11 / 41)$, with white blood cells values ranging from 7 to $114 / \mu l^{20}$ Oligoclonal bands were reported in 21 cases. Hyponatremia was rare and reported in only three cases. ${ }^{16,30,40}$ It was severe in one patient, with a value as low as $107 \mathrm{mmol} / \mathrm{l} .{ }^{16}$ It was associated with lung cancer in another. ${ }^{30}$ Voltage-gated potassium channels (VGKC) antibodies were negative for the three cases.

GAD65 antibodies were reported positive in serum and CSF in 35 cases (with available index in 19), in serum only in 18, and in CSF only in three. ${ }^{14,43}$ For two cases, results were not clearly mentioned. ${ }^{39}$ For three patients with diabetes, a GAD65-positive result was only described for serum. ${ }^{14,24,41}$ Overall, neuronal antibodies other than GAD65 were explicitly tested in a variable proportion of cases, ranging from $9 \%$ to $83 \%$ (Table 4 ).

Concurrent antibodies were reported in 11 cases $(11 / 58,19 \%$, details in Table 5). We did not find significant differences for sex, age, main clinical features, autoimmunity, and association with cancer between cases with and without concurrent antibodies (details in Supplementary Table 9). Antibodies against VGKC were positive in three patients, ${ }^{17,32} \mathrm{GABA} B$ receptor $\left(\mathrm{GABA}_{\mathrm{B}} \mathrm{R}\right)$ antibodies in three, ${ }^{14,39}$ and $\mathrm{GABA}_{\mathrm{A}} \mathrm{R}$ antibodies in five. ${ }^{14}$ Testing for $\mathrm{N}$-methyl-D-aspartic receptor (NMDAR), $\alpha$-amino-3hydroxy-5-methyl-4-isoxazoleproprionic acid receptor (AMPAR), and onconeuronal antibodies were all negative. However, we suspected that one case ${ }^{31}$ retrospectively tested positive for AMPAR in an ulterior study $^{12}$ (because of the description of same age, sex, and clinical features). Moreover, in patients with cancer, other antibodies were positive in one-half of the cases (3/6): $\mathrm{GABA}_{\mathrm{B}} \mathrm{R}^{39}$ in two SOX-1 ${ }^{39}$ and CRMP3/ $\mathrm{CRMP}^{29}$ in one case each.

\section{Treatment and Outcome}

In limbic encephalitis associated with GAD65 antibodies, many patients suffered from severe and nonremitting neurologic impairment. Several different treatments were used with variable outcome (Table 6). Duration of follow-up varied from 0 to 96 months. In five cases $(9 \%, 5 / 58)$, outcome was unknown $(\mathrm{n}=53)^{14,16,23,39}$ and treatment was not reported in 3 cases $(n=55) .^{14,23}$ 


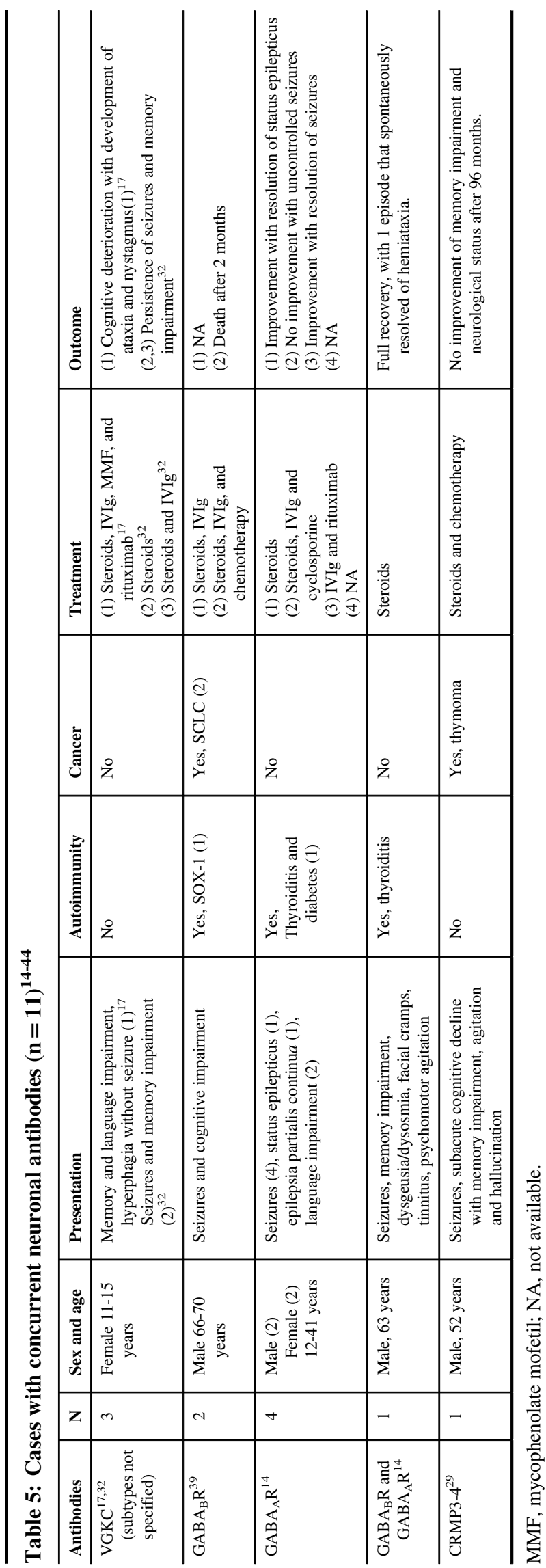

Full recovery was reported in four patients $(8 \%, 4 / 53)$, with follow-up ranging from $3^{24,25}$ to about 80 months. ${ }^{14,30}$ Three of them received immunotherapy: steroids only, ${ }^{14}$ steroids with intravenous immunoglobulin (IVIg) ${ }^{24}$ and steroids, and IVIg with plasma exchange. ${ }^{25}$ One patient did not receive any immunosuppressant and had a spontaneous remission $(2 \%, 1 / 53) .{ }^{30}$ Death was also reported in four cases $(8 \%, 4 / 53)$; it was associated with cancer in three. ${ }^{28,30,39}$ The other case was in the pediatric population. ${ }^{15}$ Improvement of initial symptoms on the last available follow-up period was found in 23 cases $(43 \%, 23 / 53$, with follow-up ranging from less than 1 month to 96 months). For 22 cases $(42 \%, 22 / 53)$, there was no improvement or worsening of the condition. Relapses were reported in nine cases $(17 \%, 9 / 53) .^{18,21,22,26-28,38,40,44}$

Favorable outcome was described in 24 patients with positive GAD65 antibodies only (24/44, 55\%, including full recovery for three patients $\left.^{24,25,30}[3 / 44,7 \%]\right)$ and in three patients with other antibodies against CNS target $\left(3 / 9,33 \%\right.$, including full recovery for one case ${ }^{14}$ $[1 / 9,11 \%])$. However, we did not find significant difference for favorable outcome between cases with and without concurrent antibodies (details in Supplementary Table 9). Moreover, in patients with positive CSF GAD65 antibodies, favorable outcome (including patients with "full recovery" and "improvement") was described in $45 \%(45 \%, 17 / 38)$ compared with $56 \%$ in cases with antibodies only positive in serum $(56 \%, 10 / 18)$. There was no significant difference between the two groups according to Fisher's exact test.

\section{Discussion}

We reported 58 cases of autoimmune limbic encephalitis associated with GAD65 antibodies in pediatric and adult populations. Most cases were young adult patients, but age ranged from 1 to 70 years of age. A coexisting systemic autoimmune condition was found in almost half of cases, mainly diabetes. This finding tends to demonstrate that those patients had a propensity to autoimmunity. Cancer was reported in $10 \%$, which is less than for LE associated with VGKC or GABA $\mathrm{R}$ antibodies. ${ }^{45}$ For onehalf of those patients, however, there were concurrent antibodies. In a recent study, the authors suggested that the probability of an underlying cancer was seven times higher in patients with GAD65 and coexisting antibodies against neuronal cell-surface antigens. ${ }^{47}$ In contrast with ovarian teratoma predicting LE associated with NMDAR antibodies, ${ }^{48}$ we found no specific type of cancer (small-cell lung cancer and malignant thymoma reported). Furthermore, seizures and memory impairment were cardinal symptoms. Status epilepticus was frequently reported (almost one of four patients), which suggests that GAD65 antibodies testing could also be helpful in this context. Cognitive impairment other than memory, such as difficulties with orientation, executive functions, and language, were possible. As opposed to LE associated with VGKC or NMDAR antibodies, characteristic movement disorders such as brachiofacial dystonia or orofacial dyskinesia were not reported. ${ }^{45,49}$ Brain MRI and EEG were usually characterized by temporal abnormalities, but multifocal abnormalities were also found. In a one-quarter of cases, pleocytosis was present, which could be as high as 114 white blood cells per microliter. Hyponatremia was possible $(5 \%)$, but less frequently than in other autoimmune LE such as LGI1 (up to $60 \%$ ). ${ }^{50}$ Overall, no distinctive patterns of clinical and paraclinical findings were found. 
Table 6: Treatment and outcome $\left(n=55^{*}\right)^{14-44}$

\begin{tabular}{|c|c|c|c|c|c|c|c|c|c|}
\hline Treatment & Number of patients & $\begin{array}{c}\text { Follow-up } \\
\text { (months) }\end{array}$ & $\begin{array}{l}\text { Outcome: } \\
\text { full recovery }\end{array}$ & $\begin{array}{c}\text { Outcome : } \\
\text { improvement }\end{array}$ & $\begin{array}{c}\text { Outcome : no } \\
\text { improvement or } \\
\text { worsening }\end{array}$ & $\begin{array}{c}\text { Outcome: } \\
\text { death }\end{array}$ & $\begin{array}{c}\text { Outcome: } \\
\text { NA }\end{array}$ & Relapse & $\begin{array}{l}\text { Favorable } \\
\text { outcome } \dagger\end{array}$ \\
\hline Steroids & $13^{14(2), 20,23(3), 26,32,36,37,14(2), 40,43(2)}$ & $<1-84$ & 1 & 5 & 7 & 0 & 0 & Yes (2) & $46 \%(6 / 13)$ \\
\hline IVIg & $4^{16,23,28,33}$ & $8-53$ & 0 & 2 & 1 & 0 & 1 & Yes (1) & $50 \%(2 / 4)$ \\
\hline PLEX & $1^{21}$ & 4 & 0 & 0 & 1 & 0 & 0 & No & $0 \%(0 / 1)$ \\
\hline Steroids + IVIg or PLEX & $18^{15(6), 21,22,23,24,28,30,34,42}$ & $1-53$ & 1 & 5 & 8 & 3 & 1 & Yes (2) & $33 \%(6 / 18)$ \\
\hline Steroids + IVIg + PLEX & $1^{25}$ & 3 & 1 & 0 & 0 & 0 & 0 & No & $100 \%(1 / 1)$ \\
\hline Steroids + PLEX + azathioprine & $1^{38}$ & 4 & 0 & 0 & 1 & 0 & 0 & Yes & $0 \%(0 / 1)$ \\
\hline Steroids + IVIg or PLEX + MMF & $1^{27}$ & 24 & 0 & 1 & 0 & 0 & 0 & Yes & $100 \%(1 / 1)$ \\
\hline Steroids + IVIg or PLEX + Rituximab & $1^{44}$ & 6 & 0 & 1 & 0 & 0 & 0 & Yes & $100 \%(1 / 1)$ \\
\hline Steroids + IVIg or PLEX + cyclophosphamide & $1^{18}$ & 12 & 0 & 1 & 0 & 0 & 0 & Yes & $100 \%(1 / 1)$ \\
\hline Steroids + IVIg or PLEX + cyclosporine & $1^{14}$ & 84 & 0 & 0 & 1 & 0 & 0 & No & $0 \%(0 / 1)$ \\
\hline Steroids + cyclophosphamide & $1^{23}$ & $6-53$ & 0 & 0 & 1 & 0 & 0 & No & $0 \%(0 / 1)$ \\
\hline Steroids + cancer treatment & $2^{29,31}$ & $36-96$ & 0 & 1 & 1 & 0 & 0 & No & $50 \%(1 / 2)$ \\
\hline Steroids + IVIg + cancer treatment & $1^{39}$ & 2 & 0 & 0 & 0 & 1 & 0 & No & $0 \%(0 / 1)$ \\
\hline IVIg + Rituximab & $1^{14}$ & $\mathrm{NA}$ & 0 & 1 & 0 & 0 & 0 & No & $100 \%(1 / 1)$ \\
\hline IVIg + azathioprine + cyclophosphamide + rituximab & $1^{19}$ & 12 & 0 & 1 & 0 & 0 & 0 & No & $100 \%(1 / 1)$ \\
\hline Steroids + IVIg + PLEX + MMF & $1^{35}$ & 24 & 0 & 1 & 0 & 0 & 0 & No & $100 \%(1 / 1)$ \\
\hline Steroids + IVIg + azathioprine + MMF & $2^{41}$ & 24 & 0 & 2 & 0 & 0 & 0 & No & $100 \%(2 / 2)$ \\
\hline Steroids + IVIg + MMF + rituximab & $1^{17}$ & 6 & 0 & 0 & 1 & 0 & 0 & No & $0 \%(0 / 1)$ \\
\hline No treatment & $3^{28,30,32}$ & 3-81 & 1 & 2 & 0 & 0 & 0 & No & $100 \%(3 / 3)$ \\
\hline
\end{tabular}

MMF, mycophenolate mofetil; NA, not available; PLEX, plasma exchange.

*Table excludes patients without details on treatment.

†Outcome including "full recovery" and "improvement."

Number of cases placed between () if more than one patients are implied. 
Furthermore, many patients suffered from severe and nonremitting neurologic impairment. Only four cases presented full recovery. Different treatments were used with very variable responses. Here, reporting an aggregate pooled effect concerning treatment could be misleading because of small samples and variable duration and description of follow-up across patients. Consequently, therapeutic strategies cannot be reasonably recommended. Also, we did not find significant difference of outcome between cases whether or not positive GAD65 antibodies were reported in CSF.

SPS is a disorder characterized by progressive muscular rigidity, predominantly of the trunk muscles, and spasms. ${ }^{51} \mathrm{~A}$ proportion of patients with GAD65 antibodies has a syndrome called SPS plus or progressive encephalomyelitis with rigidity and myoclonus, which is similar to SPS with rigidity with also stimulus-sensitive myoclonus, brainstem signs, and autonomic disturbance. ${ }^{52}$ In this review, we did not find much overlap among the three syndromes. Clinical spectrum appeared to be fairly different, except for three cases. Muscle stiffness was reported in a 63-year-old female who presented seizures with generalized abnormalities on EEG, disorientation, and dysarthria. ${ }^{24}$ She also had psychiatric manifestations such as social withdrawal, insomnia, episodes of purposeless crying, visual hallucinations, and paranoid delusions. GAD65 antibodies were highly positive in serum, but not explicitly tested in CSF. Oligoclonal bands were found. Brain MRI was normal. At 3 months, full recovery was observed after a treatment with steroids and IVIg. For the second case, a 12-year-old male patient had a diagnosis of SPS 7 years before the episode of LE. ${ }^{14}$ He had right temporal seizures. Brain MRI was abnormal with hippocampal high T2/fluid attenuated inversion recovery signal. Partial improvement of SPS symptoms was observed with resolution of seizures with treatment, consisting of anticonvulsants, IVIg, and rituximab. In both cases, there was no cancer, and GAD65 antibodies were positive only in serum, but not explicitly tested in CSF. One had concurrent type 2 diabetes. $^{24}$ Myoclonus were reported in three cases $^{20,26,37}$ and appeared to be part of seizure manifestations. In a 23-year-old female, it was associated with diffuse hyperreflexia and brainstem signs. ${ }^{37}$ In comparison with SPS, we found that LE with GAD65 antibodies was also associated with systemic autoimmune disorder. ${ }^{48}$ Risk of cancer was another similarity. ${ }^{53}$ Indeed, in this review, patients with cancer were all men with a mean age of 61 years old (median at 68 years of age, age spectrum 38-70 years old) and coexisting neuronal antibodies in 50\% (Supplementary Table 8).

Concerning paraclinical features, GAD65 antibodies were positive for almost all cases, mainly in CSF. In about $30 \%$ of cases, antibodies were not clearly tested in CSF, including three patients with diabetes. However, the presence of antibodies in the circulation does not mean that they play a pathophysiological role in a brain-related syndrome. A certain rate of transfer can be expected in healthy subjects with an intact blood-brain barrier. ${ }^{54}$ In a recent study with a focus on some autoantibodies in the serum of healthy and neuropsychiatrically ill subjects, GAD65 antibodies were comparably detectable in both groups studied. ${ }^{55}$ Consequently, detection of significant antibodies titers in CSF might be necessary to determine a causal relationship between antibodies and a central nervous system disorder such as encephalitis. ${ }^{56}$ In addition, some authors proposed that GAD65 antibodies are not the pathogenic key, considering that antibodies for intracellular antigens are rarely thought to be pathogenic. ${ }^{11,13,14,46}$
Instead, they suggest that other cell-surface antibodies (such as against AMPAR, GABA $\mathrm{B}$, and more recently $\mathrm{GABA}_{\mathrm{A}} \mathrm{R}$ ) coexist in patients with autoimmune LE. In this review, other relevant antibodies were reported in almost one patient of five. For this group, we did not find significant differences for sex, age, clinical features, autoimmunity, association with cancer, and outcome, which is under consideration for a small sample. Most importantly, we found that those relevant antibodies were not tested in every case.

There are several limitations to this work. Obviously, there are inherent limitations of case reviews. Identified cases were diverse in their degree of description of clinical features, investigation, and outcome. This was particularly significant for outcome data. Vocabulary also differed from one article to another and could have led to a certain degree of interpretation. Moreover, primary authors were not contacted to confirm the accuracy of abstracted data or to provide additional relevant data. Another important methodological limitation was that the review was carried out by only one person. Furthermore, only cases in English from the Medline database were considered; it is plausible that published cases were missed. Inclusion of studies with retrospective or prospective immunological analysis increased the sample, but might have caused duplication of cases. Clinical descriptions were also often briefer. There are also limitations associated with the statistical analyses concerning subgroups because of small sample size and statistical power. Finally, reporting bias must be discussed. Overreporting of "exceptional" with more severe clinical features is possible. Status epilepticus, which was reported in $24 \%$, might be an example. Moreover, overreporting of cases with more favorable responses to therapy cannot be excluded.

\section{Conclusion}

Our review of the literature demonstrated that LE associated with GAD65 antibodies occur across the age spectrum, and commonly occurs in association with systemic autoimmune disease, particularly diabetes. Limbic encephalitis was frequently refractory to standard immunotherapies, and recovery was often incomplete. Concurrent autoantibodies such as $\mathrm{GABA}_{\mathrm{B}} \mathrm{R}$, $\mathrm{GABA}_{\mathrm{A}} \mathrm{R}$, and VGKC were described in $19 \%$ of tested cases, with recovery (partial or complete) reported in $33 \%$ of these patients. Moreover, we found that the vast majority of cases were not tested for all those cell-surface antibodies. The detection of additional disease-associated autoantibodies may further guide treatment, acknowledging that the pathogenicity of GAD65 antibodies has not been convincingly shown. Prospective studies recruiting patients with autoimmune-mediated LE are needed to better elucidate the contributions of GAD65 autoantibodies to LE, and to evaluate treatment and outcomes in this population.

\section{Disclosures}

M-MG has received honoraria and served as a medical record reviewer for Grifols Canada. MS served as a speaker for and received speaker fees from UCB Canada and Serono.

\section{ACKNOWLEDGMENTS}

We are grateful for the contribution of the Clinical Research Platform (CRP) of the CHU de Quebec for the statistical support. 


\section{SUPPLEMENTARY MATERIAL}

To view supplementary material for this article, please visit http://dx.doi.org/10.1017/cjn.2016.13

\section{REFERENCES}

1. Brierley JB, Corsellis JAN, Hierons R, Nevin S. Subacute encephalitis of later adult life mainly affecting the limbic areas. Brain. 1960;83:357-68

2. Dalmau J, Rosenfeld MR. Paraneoplastic syndromes of the CNS. Lancet Neurol. 2008;7:327-40.

3. Graus F, Saiz A, Dalmau J. Antibodies and neuronal autoimmune disorders of the CNS. J Neurol. 2010;257:509-17.

4. Bien CG, Elger CE. Limbic encephalitis: a cause of temporal lobe epilepsy with onset in adult life. Epilepsy Behav. 2007;10:529-38.

5. Gultekin SH, Rosenfeld MR, Voltz R, et al. Paraneoplastic limbic encephalitis: neurological symptoms, immunological findings and tumour association in 50 patients. Brain. 2000;123:1481-94.

6. Graus F, Saiz A, Dalmau J. Antibodies and neuronal autoimmune disorders of the CNS. J Neurol. 2010;257:509-17.

7. Mitoma H, Song SY, Ishida K, Yamakukuni T, Kobayashi T, Mizusawa H. Presynaptic impairment of cerebellar inhibitory synapses by autoantibody to glutamate decarboxylase. J Neurol Sci. 2000;175:40-4.

8. Yoshimoto T, Doi M, Fukai NI, et al. Type 1 diabetes mellitus and drug-resistant epilepsy: presence of high titer of anti-glutamic acid decarboxylase autoantibodies in serum and cerebrospinal fluid. Internal Medicine. 2005;44(11):1174-7.

9. Solimena M, Folli F, Denis-Donini S, et al. Autoantibodies to glutamic acid decarboxylase in a patient with stiffman syndrome, epilepsy, and type I diabetes mellitus. New Engl J Med. 1988; 318:1012-20

10. Vincent A, Bien CG, Irani SR, Waters P. Autoantibodies associated with diseases of the CNS: new developments and future challenges. Lancet Neurol. 2011;10:759-72.

11. Birand B, Cabre P, Bonnan M, et al. A new case of cerebellar ataxia with anti-GAD antibodies with corticosteroids and initially seronegative. La Revue Méd Interne. 2006;27:616-9.

12. Alexopoulos $\mathrm{H}$, Akrivou S, Dalakas MC. Glycine receptor antibodies in stiff-person syndrome and other GAD-positive CNS disorders. Neurology. 2013;81:1962-4.

13. Lai M, Hughes EG, Peng X, et al. AMPA receptor antibodies in limbic encephalitis alter synaptic receptor location. Ann Neurol. 2009;65:424-34

14. Petit-Pedrol M, Armangue T, Peng $X$, et al. Encephalitis with refractory seizures, status epilepticus and antibodies to the $\mathrm{GABA}_{\mathrm{A}}$ receptor: a case series, characterisation of the antigen, and analysis of the effects of antibodies. Lancet Neurol. 2014;13:276-86

15. Lin JJ, Lin KL, Hsia SH, et al. CHEESE Study Group. Antiglutamic acid decarboxylase antibodies in children with encephalitis and status epilepticus. Pediatr Neurol. 2012;47:252-8.

16. Finelli PF. Autoimmune limbic encephalitis with GAD Antibodies. Neurohospitalist. 2011:1:178-81

17. Mirabelli-Badenier M, Morana G, Pinto F, et al. Anti-glutamic acid decarboxylase limbic encephalitis without epilepsy evolving into dementia with cerebellar ataxia. Arch Neurol. 2012;69:1064-6.

18. Kanter IC, Huttner HB, Staykov D, et al. Cyclophosphamide for antiGAD antibody-positive refractory status epilepticus. Epilepsia. 2008;49:914-20.

19. Garcìa Garcìa ME, Catrillo SM, Morales IG, et al. Acute amnesia and seizures in young female. Epileptic Disord. 2013;15:55-60.

20. Marchiori GC, Vaglia A, Vianello M. Encephalitis associated with glutamic acid decarboxylase autoantibodies. Neurology. 2001; $56: 814$

21. Matà S, Muscas GC, Naldi I, et al. Non-paraneoplastic limbic encephalitis associated with anti-glutamic acid decarboxylase antibodies. J Neuroimmunol. 2008;199:155-9.

22. Akman C, Patterson M, Rubinstein A, Herzog R. Limbic encephalitis associated with anti-GAD antibody and common variable immune deficiency. Develop Med Child Neurol. 2009;51:563-7.
23. Malter MP, Helmstaedter C, Urbach $\mathrm{H}$, et al. Antibodies to glutamic acid decarboxylase define a form of limbic encephalitis. Ann Neurol. 2010;67:470-8.

24. Cikrikçili U, Ulusoy C, Turan S, et al. Non-convulsive status epilepticus associated with glutamic acid decarboxylase antibody. Clin EEG Neurosci. 2013;44:232-6.

25. Olson JA, Olson DM, Sandborg C, et al. Type 1 diabetes mellitus and epilepsia partialis continua in a 6 -year-old boy with elevated antiGAD65 antibodies. Pediatrics. 2002;109:50.

26. Baglietto MG, Mancardi MM, Giannattasio A, et al. Epilepsia partialis continua in type 1 diabetes: evolution into encephalopathy with continuous spike-waves during slow sleep. Neuroll Sci. 2009;30:509-12.

27. Blanc F, Ruppert E, Kleitz C, et al. Acute limbic encephalitis and glutamic acid decarboxylase antibodies: a reality? J Neurol Sci. 2009;287:69-71.

28. Saiz A, Blanco Y, Sabater L, et al. Spectrum of neurological syndromes associated with glutamic acid decarboxylase antibodies: diagnostic clues for this association. Brain. 2008;131: 2553-63.

29. Knudsen A, Bredholt G, Storstein A, et al. Antibodies to CRMP3-4 associated with limbic encephalitis and thymoma. Clin Exp Immunol. 2007;149:16-22.

30. Graus F, Saiz A, Lai M, et al. Neuronal surface antigen antibodies in limbic encephalitis. Neurology. 2008;71:930-6.

31. Ances BM, Vitaliani R, Taylor RA, et al. Treatment-responsive limbic encephalitis identified by neuropil antibodies: MRI and PET correlates. Brain. 2005;128:1764-77.

32. Haberlandt E, Bast T, Ebner A, et al. Limbic encephalitis in children and adolescents. Arch Dis Child. 2011;96:186-91.

33. Lopez-Sublet M, Bihan H, Reach G, et al. Limbic encephalitis and type 1 diabetes with glutamic acid decarboxylase 65 (GAD65) autoimmunity: improvement with high-dose intravenous immunoglobulin therapy. Diabetes Metab. 2012;38:273-5.

34. Sharma A, Dubey D, Sawhney A, Janga K. GAD65 positive autoimmune limbic encephalitis: a case report and review of literature. J Clin Med Res. 2012;4:424-8.

35. Korff CM, Parvez P, Cisamoni L, et al. Encephalitis associated with glutamic acid decarboxylase autoantibodies in a child: a treatable condition? Arch Neurol. 2011;68:1065-8.

36. Giometto B, Nicolao P, Macucci M, et al. Temporal lobe epilepsy associated with glutamic-acid-decarboxylase autoantibodies. Lancet. 1998:352:457.

37. Monnerat BZ, Velasco TR, Nakano FN, et al. Opercular myoclonicanarthric status epilepticus due to glutamic acid decarboxylase antibody-associated encephalitis. Epileptic Disord. 2013;15: 342-6.

38. Mazzi G, De Roia D, Cruciatti B, Matà S, Catapano R. Plasma exchange for anti GAD associated non paraneoplastic limbic encephalitis. Transfusion and Apheresis Science. 2008;29: 229-3.

39. Boronat A, Sabater L, Saiz A, et al. $\mathrm{GABA}_{B}$ receptor antibodies in limbic encephalitis and anti-GAD-associated neurologic disorders. Neurology. 2011;76:795-800.

40. Cianci V, Labate A, Lanza P, et al. Non-paraneoplastic limbic encephalitis characterized by mesio-temporal seizures and extra-temporal lesions: a case report. Seizure. 2010;19:446-9.

41. Saidha S, Murphy S, Ronayne A, et al. Treatment of anti-glutamic acid decarboxylase antibody-associated limbic encephalitis with mycophenolate mofetil. J Neurol. 2010;257:1035-8.

42. Markakis I, Alexopoulos H, Poulopoulou C, et al. Immunotherapyresponsive limbic encephalitis with antibodies to glutamic acid decarboxylase. J Neurol Sci. 2014;343:192-4.

43. Pandit AK, Ihtisham K, Garg A, et al. Autoimmune encephalitis: a potentially reversible cause of status epilepticus, epilepsy, and cognitive decline. Ann Ind Acade Neurol. 2013;16:577-84.

44. Mishra N, Rodan LH, Nita DA, et al. Anti-glutamic acid decarboxylase antibody associated limbic encephalitis in a child: expanding the spectrum of pediatric inflammatory brain diseases. J Child Neurol. 2014;29:677-83.

45. Rosenfeld MR, Dalmau J. Anti-NMDA-Receptor Encephalitis and Other Synaptic Autoimmune Disorders. Curr Treat Options Neurol. 2011;13(3):324-32. 
46. Vincent A, Bien CG, Irani SR, Waters P. Autoantibodies associated with diseases of the CNS: new developments and future challenges. Lancet Neurol. 2011;10:759-72.

47. Arino H, Höftberger R, Gresa-Arribas N, et al. Paraneoplastic neurological syndromes and glutamic acid decarboxylase antibodies. JAMA Neurol. 2015;72:874-81.

48. Dalmau J, Tuzun E, Wu HY, et al. Paraneoplastic anti-N-methyl-Daspartate receptor encephalitis associated with ovarian teratoma. Ann Neurol. 2007;61:25-36.

49. Andrade DM, Tai P, Dalmau J, Wennberg R. Tonic seizures: a diagnostic clue of anti-LGI1 encephalitis? Neurology. 2011;76:1355-7.

50. Lai M, Huijbers MG, Lancaster E, et al. Investigation of LGI1 as the antigen in limbic encephalitis previously attributed to potassium channels: a case series. Lancet Neurol. 2010;9:776-85.

51. Hadavi S, Noyce AJ, Leslie RD, Giovannoni G. Stiff person syndrome. Pract Neurol. 2011;11:272-82.
52. Carvajal-Gonzalez A, Leite MI, Waters P, et al. Glycine receptor antibodies in PERM and related syndromes: characteristics, clinical features and outcome. Brain. 2014;137:2178-92.

53. Baizabal-Carvallo JF, Jankovic F. Stiff-person syndrome: insights into a complex autoimmune disorder. J Neurol Neurosurg Psychiatry. 2015;86:840-8.

54. Reiber H, Peter JB. Cerebrospinal fluid analysis: disease-related data patterns and evaluation programs. J Neurol Sci. 2001;184:101-22.

55. Dahm L, Steiner J, Stepniak B, et al. Seroprevalence of autoantibodies against brain antigens in health and disease. Ann Neurol. 2014; 76:82-94.

56. Gresa-Arribas N, Titulaer MJ, Torrents A. Antibody titres at diagnosis and during follow-up of anti-NMDA receptor encephalitis: a retrospective study. Lancet Neurol. 2014;13: 167-77. 